\title{
Areas of correction and development work with intellectually gifted students
}

\author{
Ekaterina Baranova ${ }^{1, *}$, Arina Shvetsova $^{2}$, Elena Afanasenkova ${ }^{2}$ \\ ${ }^{1}$ Russian State Agrarian University - Moscow Timiryazev Agricultural Academy, Russia \\ ${ }^{2}$ Sakhalin State University, Yuzhno-Sakhalinsk, Russia
}

\begin{abstract}
Justification of research objectives: One of the important components of a modern professional is the ability for high social adaptation in the context of teamwork and the promotion of their own ideas, products of activity in the labor market and in a wide sphere of social interaction. Often, a gifted person has difficulties in the system of social interaction and adaptation. This contradiction does not allow them to maximize their potential in their chosen profession, and also complicates the sphere of personal communication. These features are exacerbated in early adolescence at the stage of professional and personal self-determination. The identified problem determined the purpose of this study: to identify the reasons for the low social adaptation of intellectually gifted students through observation and psychodiagnostics; to identify current trends in correctional and developmental work; to formulate recommendations on the organization of effective psychological and pedagogical support of high school students in order to increase the level of their social adaptation at the stage of educational and professional training. Research methods: method of theoretical analysis and generalization; formative experiment; free observation in teaching practice; techniques: R. Amthauer's TSI (subtests 2, 3 and 6) and an option for adults of D. Veksler's scale; social and psychological adaptation of K. Rogers and R. Diamond; «Purpose-in-Life Test» (Crumbaugh \& Maholic); methods of mathematical statistics: calculation of Wilcoxon's T-test; Spearman's rank correlation method. Research results: the selected diagnostic tools made it possible to establish that the main range of problems of gifted students is in the field of social development and adaptation. These results made it possible to determine the main areas of correctional and developmental work and ways to overcome them: development of goal-setting, teaching students to use their intellectual abilities to solve social problems. Key findings and their significance. The main areas of correctional and developmental work lie in the development of communication skills, increasing the level of social maturity through the expansion of strategies and tactics of effective social behavior.
\end{abstract}

\footnotetext{
* Corresponding author: baranovaem@rgau-msha.ru
} 


\section{Introduction}

Requirements for a university graduate on the part of an employer in a modern dynamic society presuppose that he has not only a set of knowledge, skills and abilities corresponding to a certain area of professional training, but also the formation of special qualities that are important for a modern specialist. In particular, such as the ability to independently identify shortcomings in the level of their professional training, the ability to build a strategy for their own professional growth and career, the skill to find ways to implement the chosen target line of their development (including professional), the ability to clearly understand, and also be able to independently exercise control for its implementation. The combination of these qualities implies that the specialist who possesses them also has a certain talent in the field of activity he is engaged in. At the same time, Eremeeva $\mathrm{Yu}$. V. points out that giftedness is "a high level of development of general abilities, it determines a person's ability to achieve high results in one or several types of activity.

In addition to giftedness, knowledge, skills and abilities are required for the successful performance of an activity" [1]. In addition, giftedness can be considered "as an integral characteristic of individuality, the dynamics of which is due to the development of the personal qualities of the gifted in interaction with the factors of his social environment at each age stage" [2]. That is, even a very gifted person will not be able to develop his giftedness outside the system of social relations, and also outside of society he will not be able to realize his potential, and in professional activity too. The modern school is actively looking for effective ways of psychological and pedagogical support for gifted students. Shatunova O.V., Sergeeva A.V. write about the originality of the manifestation of each talented schoolchild and the objective need for special training of teachers and the formation of their professional competencies for successful work with gifted students [3]. The issues of identifying and supporting gifted students are systematically considered in the "Working Concept of Giftedness", the authors of which also focus on individual characteristics and possible approaches to working with gifted ones [4].

In Russian psychology, works of Bogoyavlenskaya D.B., Shadrikov V. D. [4], Larionova L.I. [5], Miklyaeva A.V. [6], Voronova T.A. [7] and others are devoted to studies of the characteristics of gifted students. However, in practical work, for example, teaching at a university, faced with the task of identifying and psychological and pedagogical support of gifted students, we do not have any established specific strategy and a sufficient set of tactical techniques for the effective implementation of this activity. The basis of this problem is the fact that diagnostics and support should be based on taking into account many components, both naturally of a general psychological and individual nature. To consider versatile qualitative and quantitative indicators in all the complexity of their interconnections, to take into account age characteristics, to identify not only the real, but also the potential capabilities of gifted university students.

Identifying the features and possible difficulties in working with gifted students is a rather urgent issue for higher education, related to the professional development of students and their social maturation, i.e., the formation of an important quality of a professional - social, and subsequently socio-professional maturity. In teaching practice, potentially gifted students with a delay or individual forms of impaired social development (social maturity) are much more common than those with a harmonious type of personal development.

In the researches of $\mathrm{H}$. Stoeger, some age-related factors in the development of giftedness are considered [8]. He notes that competent help and support of parents and teachers contribute to the realization of high intellectual potential in the academic achievements of children studying in elementary grades. A. Ziegler and H. Stoeger showed that in the early stages of teaching gifted children, external social factors play the main role, which at later stages, interacting with internal ones, transform intellectual potential into achievements [8]. 
Gabriela Kelemen is one of the modern foreign authors who develop teaching models for gifted children aimed at their harmonious development [9]. That is, they emphasize the need to harmonize the development of this category of children, inclined to deepen into one area.

In modern domestic psychology, researchers are also actively studying the options and possibilities for the full development of gifted children and adolescents, as well as the difficulties of this process. So, in her studies Sudneva O.Yu. notes that the developed evaluative function in gifted children "can be expressed in too high demands in relation to oneself, excessive self-criticism and dissatisfaction with oneself", further, the author points out that "a sense of their own inferiority, unrealistic goals are frequent problems of gifted children, which are accompanied by a pessimistic worldview, sensitivity, suspiciousness and vulnerability" [10].

The difficulty of studying this issue also lies in the difficulty of differentiating concepts in the psychology of giftedness, in their different interpretation by different authors. Also "there are different types of abilities and a very large number of activities in which they can manifest. The inclinations and abilities of people are manifested in completely different ways, their development and expression are influenced by a variety of factors" [11].

Yurkevich V.S. notes the facts of significant difficulties of gifted children and adults in situations of social contacts. In his studies, he considers the reasons for such contradictions, and as the main one he emphasizes the presence of two different options (types) of age-related development of mentally gifted individuals. If in one case these are "a kind of "super-fullfledged" children developing very harmoniously, including from the point of view of social skills, then in the other, these are problem children who have a clear developmental desynchrony, manifested in a sharp lag in emotional and social development from the mental sphere" [12]. Studies of the features of social integration of intellectually gifted students, emphasizes Yurkevich V. S., allows us to talk about "pronounced disorders and the need to search for ways to use the cognitive potential of such students for the task of objective assessment, correction and development of their social intelligence and personal qualities. "At the student age, students have a high need for self-realization, an active search for life strategies, which is, in a way, the result of the preschool and school stages of socialization, training and education. In adolescence, on the one hand, all violations of socialization are already clearly manifested in maladaptive defense mechanisms and personality traits, on the other hand, young people are prone to reflection and are ready to work on themselves and to change themselves consciously, purposefully, and independently (according to their own scenario, understanding). Therefore, it is extremely important for gifted university students, in addition to professional competencies, to form social competence. Which, Gushchina T. $\mathrm{N}$. defines as "a person's ability to achieve their own goals in the process of interacting with other people, maintaining constructive relations with them in any situations" [13].

The study by Bodryakov V.Yu., Nigmatullina E.N., Fomina N.G. [14] substantiates the need to improve the education system, including higher education, which would allow gifted students to freely express their characteristics, develop along an individual trajectory due to the uniqueness his talent.

Purpose of the study: to identify the reasons for the low social adaptation of intellectually gifted students through observation and psychodiagnostics; on the basis of the established features, to determine the most relevant areas of correctional and developmental work with intellectually gifted students and to develop recommendations in the field of educational and professional training and the organization of psychological and pedagogical support for this group of high school students. 


\section{Materials and methods}

The research was carried out among 2-4-th year students studying at Federal State-Funded Educational Institution of Higher Professional Education "Sakhalin State University". To achieve this goal, we selected a group of 27 students with high intellectual potential using the following methodological tools. Free observation in the process of teaching, techniques of R. Amthauer's TSI (subtests 2, 3 and 6) and the version for adults of the D. Veksler's scale.

Social adaptation and its components, in our opinion, constitute a conglomerate of characteristics that determine social success, activity and individual initiative. As a technique that gives us a guideline in the construction of correctional work, we have chosen method of socio-psychological adaptation of Rogers, Carl R., and Rosalind F. Dymond in order to diagnose a complex of psychological manifestations accompanying the process of social and psychological adaptation of a person.

To determine the level of development of goal-setting as a significant criterion of social maturity, we used the appropriate scale in the methodology «Purpose-in-Life Test (Crumbaugh \& Maholick, 1964).

Formative part of research work included conducting correctional developmental group and individual lessons, consultations, aimed at: 1) identification of common and individual problem areas in the personal development of gifted students, 2) selection and implementation of the most relevant areas and activities in correctional and developmental work with intellectually gifted students who have difficulties in social adaptation (insufficient level of development of social maturity).

Methods of mathematical statistics: Calculation of the Wilcoxon T-test to identify the effectiveness (statistically significant differences in the indicators of social integration before and after) of the carried-out correction and development work; Spearman's rank correlation to conduct a correlation analysis to calculate indicators of the level of development of goalsetting of gifted students and their level of social adaptation.

\section{Results}

In the process of conducting individual and group work with gifted students, with all the originality and uniqueness of the personality of each of them, we have formulated some generalized conclusions that allow us to identify the main problem areas in the field of social interaction and can be useful for choosing the areas of psychological and pedagogical support of intellectually gifted students of higher school. So, N.N. Vasyagina notes that at the stage of youth, the main task is to solve social problems. This "is due to the fact that during the period under consideration the individual first comes into direct contact with society. These social tasks include the acquisition of a profession, a certain social status, as well as the creation of a family. A young person begins to take part in adult life, reaching a state that is commonly referred to as social maturity, which presupposes the individual's ability to fulfill social responsibilities, as well as take responsibility for his own life and decisions [15]. The significant factors that determine the well-being and harmony of personal development in this age period include temperamental characteristics, the presence of difficulties in the parental family and physical features of appearance, as well as a subjective attitude towards oneself - self-esteem.

Many intellectually gifted students in childhood were called "prodigies" by those around them for their earlier speech development, the ability to reason and draw general conclusions. During the school period, almost all of the respondents surveyed experienced a fading away of "admiring" responses from significant adults, which turned into a more neutral or even detached attitude towards them. "Weird" - such a definition was heard by many participants in the study group (22 out of 27 respondents indicated this). Only those gifted individuals 
who have a bright sanguine temperament, that is, because of their extroversion, are socially active in communication, did not seem "weird" to those around them.

"Weirdness" is often the result of unusual, sometimes difficult and incomprehensible to peers and adults (primarily teachers, parents), hobbies of gifted students, but completely exciting them. Such hobbies as, for example, taking notes of historical articles from encyclopedias, sketching and describing insects of their region, passion for Vedic philosophy or Japanese poetry "Tanka", "Haiku", etc., cut off the child into the zone of social exclusion. But it is these "unusual" hobbies that constitute a developing component in their giftedness. This contradiction is one of the most difficult tasks in the implementation of effective psychological and pedagogical support for this category of students. If parents do not understand the intellectual potential of their child, perceive him as a "weird", "stranger" in their own family, then a feeling of false guilt, resentment and, as a result, auto aggressive and / or depressive tendencies in behavior are recorded in the child's personality. Therefore, in order to form a more complete picture of the study of the personality of intellectually gifted students, advisory work should be carried out in the field of parent-child relations, to raise and stimulate the solution of questions about life and professional plans for gifted students, to develop their ability to set goals, expand their ideas about life strategies in relation to the possibilities of self-realization.

When analyzing the results of the "Purpose-in-Life Test" of James Crumbaugh and Leonard Maholic we got noticeable gender differences. The results are presented in the table as arithmetic means.

Table 1. Average results according to the method of J.Crumbaugh and L.Maholic.

\begin{tabular}{|c|c|c|}
\hline \multirow{2}{*}{ Subscales } & \multicolumn{2}{|c|}{ Average scores } \\
\cline { 2 - 3 } & boys & girls \\
\hline Goals in life & 28 & 36 \\
\hline Life process & 24 & 32 \\
\hline Life performance & 22 & 28 \\
\hline Locus of control - I (Self) & 18 & 23 \\
\hline Locus of control - Life & 26 & 32 \\
\hline $\begin{array}{c}\text { General indicator of the } \\
\text { meaningfulness of life }\end{array}$ & 93 & 124 \\
\hline
\end{tabular}

From the presented results it can be seen that all the respondents have a level of development of goal-setting below the normative ones. The general level of meaningfulness of life is low in $85 \%$ of optants. This indicator, as well as the low level of the internal locus of control, allows one to judge about social infantilism, a low level of willingness to take responsibility for their lives, events and actions among intellectually gifted students. This leads us to the conclusion that it is necessary to develop the level of social adaptation, social maturity and subjectivity in this category of university students.

Based on the results of the methodology of social and psychological adaptation by K. Rogers and R. Diamond the following results were revealed. Among intellectually gifted students, the level of social adaptability is low for $81 \%$ of the respondents and the average for the remaining 19\%. In the surveyed group, low rates were also found on the scale of "disadaptation". This indicates inadequately formed or contradictory ideas about themselves among the surveyed students, their inability to objectively assess their personal qualities associated with social adaptation. 
On the scales "acceptance" - "rejection" of oneself, similar results were obtained - a low acceptance rate of $70 \%$ and an average of $30 \%$, hence, self-doubt in various social situations, and often simply a tendency to avoid of a new social experience.

The features revealed in the course of diagnostics in terms of the level of sociopsychological adaptation of intellectually gifted university students indicate that they have some personal diffusion, the absence of clearly formed ideas about their personality traits and boundaries. This, in our opinion, is due to their lack of a well-formed system of positive, socially significant and approved guidelines, role models. They are pretty clear about what they don't want to be. More often this is expressed by phrases: "I don't want to be like everyone else," "I don't want to be like my parents," etc., but they cannot express what they want to be accurately and consciously. This suggests that this group of respondents does not have a clearly formed positive image "The Future Self" (The Ideal Self). For intellectually gifted students, an increased tendency in the severity of indicators of statements and escapism (a high rate in $66 \%$ ) - the avoiding of problems, which complements the picture of social infantilism.

In the course of the research, we conducted a correlation analysis to calculate Spearman's rank correlation of indicators on the level of development of goal-setting of gifted students and their level of social adaptation, in order to identify their interconnection. Coefficient rs $=0.51$, falling into the zone of statistical significance, confirms the presence of a significant relationship. Thus, we relied on the idea that it is the development of goal-setting that makes it possible to see and realize the prospects for personal self-realization and professional development. Purpose gives meaning to life, strategic vision of time perspective, gives direction to life. The directed development in the educational process of the university of the ability to set goals in students will create a clear need to be included in various social situations with a full understanding of their goals and objectives, and the success of their achievement, create a positive experience, which in general will contribute to the formation of confidence in social development and adaptation.

The conducted methods allowed us to outline the areas of correctional and developmental work with intellectually gifted university students, to select individual and group methods for developing the level of social adaptation (social maturity).

The purpose of our practical work was to increase the level of social integration of intellectually gifted university students in each area of correctional and developmental work we identified. As part of this work, it was important to find effective ways to direct their logical intelligence to solve the problem: objective assessment, correction and development of their social intelligence and personal qualities, ensuring a sufficient (if possible high) level of social adaptation and social interaction. Logical intelligence (or logical-mathematical according to G. Gardner) - is a natural strength of intellectually gifted students, their resource, therefore, directing it to social development, teaching students to independently build and organize their social development, productive social interaction and comfortable social space - we see it as the main area of correctional and developmental work. That is, to make them subjects of their own social development.

A necessary condition for carrying out correctional and developmental work with intellectually gifted students is the formation of a zone of confidence. Provided that, on the part of intellectually gifted students, confidence in the psychologist is formed, they begin to show a willingness not only to try, but also purposefully, systematically work on themselves. They subjectively accept an approach to this process as to the search for solutions to a set of social problems.

Another important and prerequisite for corrective development work is an individual approach. This is due to the fact that intellectually gifted students - these are unique bright personalities with a high level of cognitive development, with well-developed defense mechanisms, aimed at effectively fencing off society, in order to preserve themselves. Their 
experience of previous social interaction, as a rule, was negative, wounded and destroyed them, therefore a kind of self-isolation became for them a way of self-preservation, a natural reaction to social "rejection" and exclusion.

As part of the implementation of correctional and developmental work, group and microgroup work (in dyads and triads) should be aimed at developing communication skills, expanding strategies and tactics of socially adaptive behavior, mastering the methods of selfregulation, managing emotions, as well as socially acceptable ways of expressing them. The main task of this stage is harmonization of the cognitive sphere of gifted students (removal of cognitive dissonances), and the main method is the area of logical intelligence to solve problems of a social plan and in the management of the emotional-volitional sphere. Individual work should be aimed at developing metacognitive functions. First of all, on the ability of intellectually gifted students to set goals, build strategies for their own life, their future, overcoming an infantile social position, forming subjectivity, looking for effective strategies and tactics aimed at achieving life goals, building trajectories of their own development and socialization. All this as a whole will allow them, already in the period of independent professional activity, to maximize their potential and realize a high level of professional self-realization. At the same time, self-realization should be considered as "a process carried out through one or another human activity through one's own efforts and cocreation, consolidation of these efforts with other people, but at the same time without losing one's own personal identity" [16]. That is, in the process of correctional and developmental work, intellectually gifted students begin to understand, through their own practical activities and interaction, those real opportunities and benefits, which they are given by competent and productive building of a system of social interaction, cooperation with other participants in the process of joint activities and solving specific social problems.

\section{Discussion}

The conducted research and the implemented correctional and developmental program showed that for the effectiveness of psychological and pedagogical support of intellectually gifted students, it is necessary to take into account the factors of social integration and their possible violations. When implementing an individual approach, it is important to identify possible difficulties in personality development, predict the consequences, and, therefore, be able to find ways to harmonize the personality, in order to increase the level of its selfrealization in various spheres of life (professional activity, family, communication, etc.). The intellectually gifted students of the university have bright and extraordinary personal characteristics, special approaches to the analysis and generalization of the surrounding world, incoming information, and therefore each of them requires an individual approach, both in diagnosis and in the choice of methods of correction and development.

On the basis of the considered theoretical approaches, practical conclusions from the study, the characteristics of the youthful age of optants and the specifics of their personal development, to violations of social integration that hinder the process of their successful self-realization we can refer as follows:

- violations in the communicative sphere: low readiness for full-fledged social interaction, understanding of the interlocutor; poorly formed skills of productive communication, etc.;

- violations in the field of role relationships: the inability to effectively carry out assigned social roles in interpersonal and business relationships;

- disorders in the field of psycho-emotional well-being: the inability to experience a state of relatively long internal emotional comfort (calmness, emotional stability, etc.) without the presence of external or internal conflicts;

violations in the socio-psychological sphere: inadequate formation of the "I" system, inability to build their own strategic goals and life plans for the future. 
Based on the method of social and psychological adaptation of K. Rogers and R. Diamond used before and after correctional development work, we assessed the effectiveness of its implementation using the Wilcoxon T-test to identify statistically significant differences in indicators. Received empirical value $\mathrm{T}_{\mathrm{emp}} 3$ is in the zone of significance, which proves the presence of a positive shift in the level of the indicator of social adaptation. Consequently, our activities are quite effective.

\section{Conclusions}

The main areas of correctional and developmental work with intellectually gifted students are in the field of social development and social integration. Disorders of social integration are interrelated with the level of development of the ability to set goals. Correctional and developmental work with disorders in the social sphere should be based on the formation of goal-setting, strategies, tactics of socially adaptive and approved behavior, as well as the formation of subjectivity in this group of students of high school.

Based on the results of individual and group work on the correction of social integration disorders and the development of the level of social adaptation in intellectually gifted students, we identified a number of recommendations.

1. Intellectually gifted students with a high level of social maladjustment avoid group meetings, even with a high readiness for individual work. As a rule, maladaptive defensive reactions are demonstrated in the training circle. In individual conversations, students admit that they are ready for a more open interaction with two or three participants, but no more. This is confirmed by practical work with this category of students. Therefore, correctional and developmental work with them should begin with micro groups - of two or three people.

2. At the heart of the social development of intellectually gifted students should be learning, associated, first of all, with the use of such techniques that will direct their logical intelligence to solving social problems as tasks, since intellectual potential is their strength and the main resource.

3. Particular attention should be paid to the expansion of strategies and tactics of social behavior and communicative interaction. To do this, one should analyze their current tactics from the point of view of their effectiveness in achieving their goals (communicative and social).

4. Intellectually gifted students are easily involved in the process of psychological introspection and are able to draw the necessary conclusions themselves with some direction, help and recommendations from a psychologist. In the course of this work, it is important to form in them not only the ability for adequate self-reflection, but also a subjective attitude to the process of their own development.

5. The creation and development of situations of positive social interaction in the course of correctional and developmental work, allows you to accumulate the necessary experience in a positive manner and relieve the anxiety of social contacts in this category of high school students in the future.

In individual practical work, we tried to direct the logical intelligence of gifted students to the task of objective assessment, correction and development of their social intelligence and personal qualities. Make them the subjects of their own harmonious development, showing the possibilities of expanding their own potential through active interaction with other participants in joint activities. After all, joint activity, in particular educational and professional (and later professional) is always a set of potential opportunities, in which each act as a resource for the other in the process of implementing certain activities and interaction. This process is provided by such internal psychological mechanisms as autonomy - selfactualization - integration ... while maintaining the self-identity of the individual, including 
the professional one. This contributes to the possibility of the personality going beyond the limits of its actual "self-image", its real possibilities in the area of potential development.

In our correctional and developmental work, we relied on the development of goal-setting and a conscious strategic approach to building one's own life. In the process of work, we came to the conclusion that it is necessary to move to a more integrative approach, which allows us to implement metacognitive processes and, above all, the development of subjectivity.

\section{References}

1. Yu.V. Eremeeva, Scientific dialogue: Young scientist. Collection of scientific papers based on the materials of the $X V$ international scientific conference. International United Academy of Sciences (Publishing house "Scientific Publications Centre of the International United Academy of Sciences", $\mathrm{SPb}, \quad 2018)$ DOI: https://doi.org/10.18411/spc-22-03-2018-11

2. V.G. Gryazeva-Dobshinskaya, V.A. Glukhova, A.S. Maltseva, P.S. Glukhov, Bulletin of SUSU. Series: Psychology 31, 41-55 (2012) DOI: https://doi.org/10.24412/Fg8xmiooyCY

3. O.V. Shatunova, A.B. Sergeeva, The Education and science journal 9, 143-154 (2014) https://doi.org/10.17853/1994-5639-2014-9-143-154

4. D.B. Bogoyavlenskaya, Working concept of giftedness 2nd ed. (M., 2003) DOI: https://doi.org/10.24412/FhFzuzY19AA

5. L.I. Larionova, Siberian Psychol. Magazine 21, 157-162 (2005) DOI: https://doi.org/10.24412/Fg5LLsWVqeU

6. A.V. Miklyaeva, V.V. Khoroshikh, E.N. Volkova, Bulletin of NSPU 9(4), 36-55 (2019) DOI: https://doi.org/10.15293/2658-6762.1904.03

7. T.A. Voronova, S.V. Dubrovina, J.V. Chepurko, The Education and science journal 20(8), 28-45 (2018) https://doi.org/10.17853/1994-56392018-8-28-45

8. A. Ziegler, H. Stoeger, Motivation, selfregulation, and excellence (promoting talent developing expertise - achieving excellence) 9, 131-152 (2011) http://psycho.ewf.unierlangen.de/mitarbeiter/ziegler/publikationen/Publikation17.pdf

9. G. Kelemen, Procedia - Social and Behavioral Sciences 2(2), 3981-3987 (2010) doi:10.1016/j.sbspro.2010.03.627

10. O.Yu. Sudneva, Russian Journal of Education and Psychology 11(19) (2012) DOI: https://doi.org/10.24412/FhF3WUQN_c4

11. Yu.V. Eremeeva, Scientific dialogue: Young scientist. Collection of scientific papers based on the materials of the XV international scientific conference (Publishing house "Scientific Publications Centre of the International United Academy of Sciences", SPb, 2018) DOI: https://doi.org/10.18411/spc-22-03-2018-11

12. V.S. Yurkevich, Modern foreign psychology 7(2), 28-38 (2018) DOI: https://doi.org/10.17759/jmfp.2018070203

13. T.N. Gushchina, Bulletin of the Kostroma State University. Series: Pedagogy. Psychology. Sociokinetics 1, 20-25

(2019)

https://cyberleninka.ru/article/n/issledovanie-rezultatov-razvitiya-sotsialnoyodaryonnosti-uchaschihsya

14. V.Yu. Bodryakov, E.N. Nigmatullina, N.G. Fomina, Pedagogical education in Russia 2, 36-42 (2010) DOI: https://doi.org/10.24412/Fg5L33xH14c 
15. E.L. Afanasenkova, N.N. Vasyagina, Pedagogical education in Russia 2, 1-30 (2019) DOI: https://doi.org/10.24412/Fg6S6QWJPPo

16. N.N. Vasyagina, E.L. Afanasenkova, J.A. Vedyashkina, S.A. Vasyagina, N.V. $\begin{array}{llllll}\text { Abramovskih, } & \text { PSYRGGU LXIV, } & 740 & - & 747 & \text { (2019) }\end{array}$ http://dx.doi.org/10.15405/epsbs.2019.07.96 